\title{
Antioxidative effects of the spice cardamom against non-melanoma skin cancer by modulating nuclear factor erythroid-2-related factor 2 and NF-кB signalling pathways
}

\author{
Ila Das $^{1}$, Asha Acharya ${ }^{2}$, Deborah L. Berry ${ }^{3}$, Supti Sen ${ }^{3}$, Elizabeth Williams ${ }^{3}$, Eva Permaul ${ }^{3}$, \\ Archana Sengupta ${ }^{1}$, Sudin Bhattacharya ${ }^{1}$ and Tapas Saha ${ }^{3 *}$ \\ ${ }^{1}$ Department of Cancer Chemoprevention, Chittaranjan National Cancer Institute, Kolkata, India \\ ${ }^{2}$ Genetarn Corporation, Rockville, MD, USA \\ ${ }^{3}$ Department of Oncology, Lombardi Comprehensive Cancer Center, Georgetown University, 3970 Reservoir Road, NW, \\ PCS Building, Room GD3, Washington, DC 20057, USA
}

(Submitted 9 May 2011 - Final revision received 28 September 2011 - Accepted 17 October 2011 - First published online 19 December 2011)

\begin{abstract}
The role of dietary factors in inhibiting or delaying the development of non-melanoma skin cancer (NMSC) has been investigated for many years. Cardamom, which is a dietary phytoproduct, has been commonly used in cuisines for flavour and has numerous health benefits, such as improving digestion and stimulating metabolism and having antitumorigenic effects. We have investigated the efficacy of dietary cardamom against 7,12-dimethylbenz[a]anthracene (DMBA)-induced skin papillomatogenesis in Swiss albino mice that closely resembles human NMSC. Mice were grouped into normal wild type (untreated), vehicle-treated (acetone), carcinogen-treated (DMBA), and DMBA and cardamom-treated (DMBA + CARD) to delineate the role of cardamom against DMBA-induced papillomatogenesis. Oral administration of cardamom to DMBA-treated mice up-regulated the phase II detoxification enzymes, such as glutathione- $S$-transferase and glutathione peroxidase, probably via activation of nuclear factor erythroid-2-related factor 2 transcription factor in 'DMBA + CARD' mice. Furthermore, reduced glutathione, glutathione reductase, superoxide dismutase and catalase were also up-regulated by cardamom in the same 'DMBA + CARD' group of mice compared with DMBA-treated mice. Cardamom ingestion in DMBA-treated mice blocked NF-кB activation and down-regulated cyclo-oxygenase-2 expression. As a consequence, both the size and the number of skin papillomas generated on the skin due to the DMBA treatment were reduced in the 'DMBA + CARD' group. Thus, the results from the present study suggest that cardamom has a potential to become a pivotal chemopreventive agent to prevent papillomagenesis on the skin.
\end{abstract}

Key words: Chemoprevention: Cyclo-oxygenase-2: Superoxide dismutase: Catalase: Glutathione: $7,12-$ Dimethylbenz[a]anthracene: Detoxification enzymes

Non-melanoma skin cancer (NMSC) is a common form of skin cancer that occurs either in basal or squamous cells. These cells are located at the epidermal layer of the skin and protect the internal organs and the outer surface of the body. Skin cancer cells vary in their proliferation rate depending upon the type of skin cancer, but rarely spread to the other parts of the body. More than 1000000 new cases and less than 1000 deaths from NMSC have been reported in the USA in $2010^{(1)}$. UVA and UVB (UV radiation) exposure to exposed skin is the leading cause of $\mathrm{NMSC}^{(2)}$. Outdoor workers, people of fair skin, large number of moles in the body, large dark-coloured birth mark known as congenital melanocytic nevus, pre-cancerous skin lesion such as actinic keratosis, family history of sunburn and skin cancer, and aged people are at a serious risk of developing skin cancer.

Oxidative stress, which is defined as an excess of toxic reactive oxygen species (ROS), and concomitant inadequate expression levels of various ROS detoxification enzymes, such as phase II detoxification and antioxidation enzymes, play a crucial role in developing several cancers including

Abbreviations: 4-HNE, 4-hydroxynonenal; CARD, cardamom-ingested; CAT, catalase; CDNB, 1-chloro-2-4-dinitrobenzene; COX-2, cyclo-oxygenase-2; DMBA, 7,12-dimethylbenz[a]anthracene; GPx, glutathione peroxidase; GR, glutathione reductase; GSH, reduced glutathione; GST, glutathione-Stransferase; IHC, immunohistochemistry; Keap1, kelch-like ECH-associated protein 1; LPO, lipid peroxides; MDA, malondialdehyde; NMSC, non-melanoma skin cancer; Nrf2, nuclear factor erythroid-2-related factor 2; ROS, reactive oxygen species; SOD, superoxide dismutase; TPA, 12-O-tetradecanoylphorbol-13-acetate.

*Corresponding author: Dr T. Saha, fax +1 202687 5324, email ts283@georgetown.edu; tapassaha2000@gmail.com 
skin carcinogenesis ${ }^{(3)}$. ROS is produced during distinct intracellular pathways and has been found to be elevated during infection, inflammation, and exposure to environmental carcinogens, radiation and sunlight ${ }^{(4)}$, which in part might lead to the development of NMSC. Cancer chemoprevention, as first defined by Sporn in $1976^{(5)}$, utilises naturally occurring phytochemicals, biological compounds and/or synthetically synthesised chemical agents to reverse, repress or prevent the development of several cancers including skin cancer. Spices and condiments are naturally occurring dried herbs that are known for their high therapeutic potential. Numerous epidemiological studies have shown that a diet rich in vegetables, fruits, herbs and spices is associated with a reduced risk of most cancers, and thus serve as potent chemopreventive agents $^{(5,6)}$.

Cardamom is a well-known aromatic spice that is regularly used in Eastern, Arab and Scandinavian cuisines for its aroma. From ancient times, it has also been used as herbal medicine especially for the common cold. Cardamom has also been used for teeth, gum and throat infection, as well as against lung congestion, pulmonary tuberculosis and digestive disorders. Cardamom is one of the common ingredients of Indian Ayurveda and Chinese traditional medicine ${ }^{(7)}$. Cardamom belongs to Elettaria and Amomum genera of the ginger family Zingiberaceae. Both forms have small spindle-like seedpod but Elettaria is smaller and light green in colour, whereas Amomum is big and blackish grey in appearance. T. John Zachariah in his chapter titled 'Chemistry of cardamom' from the book Cardamom, The Genus Elettaria ${ }^{(8)}$ had compiled different components of cardamom that have been investigated and published earlier. The main chemical ingredients of cardamom is the oil component that is composed of $\alpha$-and $\beta$-pinene, $\alpha$-phellandrene, sabinene, limonene, myrcene, 1,8-cineole, $\boldsymbol{\gamma}$-terpinene, p-cymene, terpinolene, linalool, terpinen-4-oil, $\alpha$-terpineol, $\alpha$-terpineol acetate, linalyl acetate, citronellol, geraniol, nerol, methyl eugenol and trans-nerolidol ${ }^{(8,9)}$. A couple of bioactive compounds of cardamom have been studied for anti-cancer, anti-inflammatory and chemopreventive properties. Monoterpene compounds of cardamom oil were shown to enhance the activity of indomethacin on skin. A lower dose of cardamom suppressed oedema to a lesser extent, whereas a higher dose of cardamom reveals a more potent anti-inflammatory effect on the skin in the presence of indomethacin $^{(10)}$. Chemopreventive function of cardamom has also been demonstrated earlier to regulate colorectal cancer $^{(11)}$. The present study was designed to evaluate the chemopreventive efficacy of nutritional cardamom on 7,12-dimethylbenz[a]anthracene (DMBA)-induced skin carcinogenesis in a well-defined mouse model ${ }^{(12)}$ that highly mimics human NMSC.

\section{Experimental methods \\ Chemicals}

DMBA, croton oil, acetone, NADPH (nicotinamide adenine dinucleotide phosphate, reduced form), pyrogallol, thiobarbituric acid, diethylene triamine penta-acetic acid and pyridine were purchased from Sigma Chemicals Company.
Animals used and dose selection for 7,12dimethylbenz[a]anthracene and cardamom

Female Swiss albino mice aged 5-6 weeks, and weighing 20-22 g were housed in plastic cages with stainless-steel wire lids (four mice per cage). The housing facility was maintained at $30^{\circ} \mathrm{C}$ temperature under alternating light and dark conditions. Standard food pellets and drinking water were provided ad libitum to all the treated/untreated mice.

\section{7,12-Dimethylbenz[a]anthracene treatment}

DMBA was purchased from Sigma Chemicals Company. In the first week, three topical applications of $100 \mathrm{nmol}$ DMBA in $100 \mu \mathrm{l}$ acetone were applied on the shaved dorsal skin. This was followed by $1 \%(\mathrm{w} / \mathrm{v})$ croton oil in acetone at the same site twice per week up to 8 weeks for the initiation and development of skin papillomatogenesis.

\section{Cardamom treatment}

Small-pod cardamom was bought from the local market (available to common people) in bulk in anticipation to complete one set of experiments ( 3 months of supply) so that the batch of cardamom does not differ between feedings to the animals. Just before the oral administration of cardamom to DMBA-treated mice, the required amount of spice was ground in a mixer and an aqueous suspension of cardamom solution was prepared fresh that contained all the oil components of cardamom as emulsion. Initially, a pilot study was carried out using different doses, namely 250, 500, 750 and $1000 \mathrm{mg}$ cardamom/kg body weight per $\mathrm{d}$, in order to standardise the most effective dose against papilloma formation during DMBA-induced skin carcinogenesis. Treatment with $500 \mathrm{mg}$ cardamom/kg body weight per mouse per $\mathrm{d}$ was found to be most effective without any toxic manifestation.

\section{Experimental design and treatment groups}

The experiments were divided into three sets such that mice can be killed after 2nd, 8th and 12th week of first DMBA application. Each set was again divided into five groups with eight mice in each group. Each set comprised forty mice that were divided into 'untreated' (normal control), 'acetone' (vehicle control), 'DMBA' (carcinogen control), 'DMBA + CARD' (DMBA-treated and cardamom-ingested) and 'CARD' (cardamom-ingested) groups. The protocol used for DMBA application on the shaved dorsal skin of Swiss albino mice, and oral administration of cardamom to wild-type and DMBA-treated mice are given in Table 1. Acetone treatment was done exactly similar to the DMBA treatment and considered as the vehicle control because DMBA was dissolved in acetone. All animal protocols have been approved by the Institutional Animal Care and Use Committee of the institution. The animals were carefully examined once per week for recording the body weight and papilloma growth. 
Table 1. Correlation between the different groups of mice, treatments and body weight (Mean values and standard deviations)

\begin{tabular}{|c|c|c|c|c|c|c|c|c|}
\hline \multirow[b]{2}{*}{ Experimental groups } & \multirow[b]{2}{*}{ Treatments } & \multirow{2}{*}{$\begin{array}{l}\text { No. of animals/ } \\
\text { duration } \\
\text { of study (weeks) }\end{array}$} & \multicolumn{2}{|c|}{$\begin{array}{l}\text { Initial average } \\
\text { weight }(\mathrm{g}) \\
\text { week } 0\end{array}$} & \multicolumn{2}{|c|}{$\begin{array}{l}\text { Average weight } \\
\text { (g), week } 8\end{array}$} & \multicolumn{2}{|c|}{$\begin{array}{c}\text { Final average } \\
\text { weight }(\mathrm{g}) \text {, week } \\
12\end{array}$} \\
\hline & & & Mean & SD & Mean & SD & Mean & SD \\
\hline Untreated (normal control) & $\begin{array}{l}\text { Water and standard food pellets during treatments } \\
\text { and serve as a untreated control }\end{array}$ & $\begin{array}{l}24 / 02 \\
24 / 08 \\
24 / 12\end{array}$ & $20 \cdot 31$ & $1 \cdot 17$ & $28 \cdot 5$ & $1 \cdot 28$ & $32 \cdot 42$ & $1 \cdot 25$ \\
\hline Acetone (vehicle-treated) & $\begin{array}{l}\text { Three topical application of acetone, followed by } \\
100 \mu \mathrm{l} \text { of } 1 \%(\mathrm{w} / \mathrm{v}) \text { croton oil in acetone at the } \\
\text { same site twice per week up to 8th week } \\
\text { and treated as 'normal' }\end{array}$ & $\begin{array}{l}24 / 02 \\
24 / 08 \\
24 / 12\end{array}$ & $20 \cdot 18$ & 0.96 & 28.05 & 1.44 & $30 \cdot 98$ & 1.29 \\
\hline DMBA (carcinogen-treated) & $\begin{array}{l}\text { Three topical application of } 100 \mathrm{nmol} \text { DMBA in } \\
100 \mu \mathrm{l} \text { acetone, followed by } 100 \mathrm{ml} \text { of } 1 \%(\mathrm{w} / \mathrm{v}) \\
\text { croton oil in acetone at the same site twice } \\
\text { per week up to 8th week and treated as 'normal' }\end{array}$ & $\begin{array}{l}24 / 02 \\
24 / 08 \\
24 / 12\end{array}$ & $20 \cdot 19$ & $1 \cdot 22$ & $22 \cdot 92$ & 0.89 & $25 \cdot 79$ & $1 \cdot 131$ \\
\hline DMBA + CARD (carcinogen and cardamom-treated) & $\begin{array}{l}\text { DMBA treatment was performed same as above. } \\
\text { In parallel, cardamom suspension was administered } \\
\text { orally to the mice simultaneously with DMBA } \\
\text { application and continued until the end of the } \\
\text { experiment (12 weeks) }\end{array}$ & $\begin{array}{l}24 / 02 \\
24 / 08 \\
24 / 12\end{array}$ & $20 \cdot 15$ & 1.01 & $26 \cdot 01$ & $1 \cdot 19$ & $29 \cdot 46^{*}$ & $1 \cdot 15$ \\
\hline CARD (cardamom-treated) & $\begin{array}{l}\text { Cardamom suspension was administered to the mice } \\
\text { without DMBA application and continued } \\
\text { until the end of the experiment ( } 12 \text { weeks) }\end{array}$ & $\begin{array}{l}24 / 02 \\
24 / 08 \\
24 / 12\end{array}$ & $19 \cdot 57$ & $1 \cdot 15$ & $27 \cdot 4$ & 0.95 & 31.45 & $1 \cdot 19$ \\
\hline
\end{tabular}

DMBA, 7,12-dimethylbenz[a]anthracene; CARD, cardamom ingested.

* Mean value was significantly different from that of the DMBA group $(P<0.001)$. 
Tissue preparation for histology with haematoxylin and eosin and immunohistochemistry

Collected skin tissues were fixed in 10\% neutral formalin for $24 \mathrm{~h}$ and then dehydrated by graded ethyl alcohol, starting from 50 to $95 \%$. The tissues were then soaked in xylene and paraffin blocks were prepared. Serial microtome sections, in the form of a paraffin ribbon, were made at a thickness of $5 \mu \mathrm{m}$. The tissues were soaked in lukewarm water $\left(58^{\circ} \mathrm{C}\right)$ for stretching, and the desired portion of the paraffin ribbon was placed on a clear glass slide previously coated with egg albumin and gently stretched using forceps or needles. Any excess water on the slide was drained off, and the slide was placed on a hot plate to allow the paraffin to dry and adhere to the slide.

Haematoxylin and eosin staining was performed with the sectioned tissues. The slides were rehydrated by graded ethyl alcohol series (from 95 to $50 \%$ ethyl alcohol) and were stained with $1 \%$ haematoxylin for $3 \mathrm{~min}$. The slides were washed slowly in running tap water for 8-10 min to develop the colour of haematoxylin that stains DNA-rich nuclei. The stained slides were then dipped in an acid-alcohol solution $\left(1: 1 \mathrm{HCl}-\mathrm{C}_{2} \mathrm{H}_{5} \mathrm{OH}\right)$ to remove extra stain and washed under running water. The haematoxylin-stained slides were again passed through ascending grades of ethyl alcohol. Counterstaining was done with eosin $(0.5 \mathrm{~g}$ in $100 \mathrm{ml}$ of $95 \%$ absolute alcohol). The slides were then treated with xylene for $15 \mathrm{~min}$ each. Mounting was performed with a small amount of DPX mounting solution over a thin $22-50 \mathrm{~mm}$ coverslip.

Immunohistochemical staining of mouse skin samples was performed with the following antibodies: nuclear factor erythroid-2-related factor 2 (Nrf2; Santa Cruz SC-722, 1:100); NF-кB (Santa Cruz SC-109, 1:75); ІкB $\alpha$ (Santa Cruz SC-371, 1:600); kelch-like ECH-associated protein 1 (Keap1; Sigma AV38981, 1:4000). A $5 \mu \mathrm{m}$ section from formalin-fixed paraffin-embedded tissues was deparaffinised with xylene and rehydrated through a graded alcohol series (from 95 to $50 \%$ ethyl alcohol). Antigen retrieval was performed by immersing the tissue sections at $98^{\circ} \mathrm{C}$ for $20 \mathrm{~min}$ in $10 \mathrm{~mm}$-citrate buffer (pH 6.0) with $0.05 \%$ Tween. Immunohistochemical staining was performed using the Vectastain Kit (Vector Labs), according to the manufacturer's instructions. Briefly, slides were pretreated with $3 \% \mathrm{H}_{2} \mathrm{O}_{2}$, avidin/biotin blocking and $10 \%$ normal goat serum, and then exposed to the stated dilution of primary antibody for $1 \mathrm{~h}$ at room temperature. The slides were exposed to appropriate biotin-conjugated secondary antibodies (Vector Labs), Vectastain ABC reagent (Vector Labs) and DAB chromagen (Dako) to detect horseradish peroxidase. The slides were then counterstained with haematoxylin (Fisher, Harris Modified Haematoxylin) at a 1:17 dilution for $2 \mathrm{~min}$ at room temperature, blued in $1 \%$ ammonium hydroxide for $1 \mathrm{~min}$ at room temperature, dehydrated and mounted with Acrymount. Consecutive sections with the omitted primary antibody were used as negative controls. Images were captured using an Olympus DP70 microscope (Olympus) at $200 \times$ magnification.

\section{Preparation of tissue lysates for immunoblotting}

Treated/untreated skin tissues from the dorsal sides were excised from each group of mice for lysate preparation. In the case of the 'DMBA' and 'DMBA + CARD' groups, skins with three to four papillomas per mice were excised to prepare the tissue lysates. This whole procedure had been repeated three times for reproducibility and statistical significance. Approximately $50 \mathrm{mg}$ of skin tissues from treated and untreated mice were excised from the different groups of mice and subsequently soaked in tissue lysis buffer (Roche Biochemicals) containing protease inhibitor cocktail (Roche Biochemicals) at $4^{\circ} \mathrm{C}$. The tissues were then homogenised for $30 \mathrm{~s}$ and then centrifuged at $14000 \mathrm{~g}$ for $20 \mathrm{~min}$ at $4^{\circ} \mathrm{C}$. The supernatants (tissue lysates) were collected into a fresh tube and stored in $-80^{\circ} \mathrm{C}$ until further use in subsequent Western blotting. Concentrations of the total proteins were measured by the Lowry method using bovine serum albumin as a standard.

\section{Methods for biochemical assays}

Skin tissues were sampled for biochemical assays from all groups of mice for the measurement of lipid peroxides (LPO), glutathione- $S$-transferase (GST), glutathione peroxidase (GPx), catalase (CAT), superoxide dismutase (SOD), glutathione reductase (GR) and reduced glutathione (GSH) as published protocols ${ }^{(12)}$. For the 4-hydroxynonenal (4-HNE) assay, generation of 4-HNE was measured by following the manufacturer's instructions using OxiSelect HNE-His Adduct Elisa Kit from Cell BioLabs.

LPO generation in mice was obtained from $400 \mathrm{mg}$ of the treated/untreated skin tissue lysates by measuring thiobarbituric acid-reactive substance, formed/mg protein using an extinction coefficient of $1.56 \times 10^{5} \mathrm{~mol} / \mathrm{l}$ per $\mathrm{cm}^{(13)}$. Thiobarbituric acid-reactive substance assay is a tool for the direct measurement of malondialdehyde (MDA) in the treated/untreated skin tissue lysates. In brief, skin tissues were washed in $0.9 \%$ $\mathrm{NaCl}$ and homogenised with nine volumes $(3.6 \mathrm{ml})$ of $1.15 \%$ $\mathrm{KCl}$, followed by centrifugation at $12000 \mathrm{~g}$ for $10 \mathrm{~min}$ at $4^{\circ} \mathrm{C}$. The supernatant was further centrifuged for $10 \mathrm{~min}$ at $10000 \mathrm{~g}$ at $4^{\circ} \mathrm{C}$. Finally, the supernatant was centrifuged at $25000 \mathrm{~g}$ at $4^{\circ} \mathrm{C}$ for $1 \mathrm{~h}$ and the precipitate was retained. The precipitate was then resuspended in $\mathrm{KCl}$ and aliquots were stored for future use. SDS, acetic acid, thiobarbituric acid and water were then added to the selected aliquots and heated at $95^{\circ} \mathrm{C}$ for $1 \mathrm{~h}$. The butanol-pyridine solution (15:1) was added to the above reaction mixture and the mixture was vortexed vigorously for $2 \mathrm{~min}$ followed by centrifugation at $3000 \mathrm{~g}$ for $10 \mathrm{~min}$. The upper organic layer was collected, and optical density at $532 \mathrm{~nm}$ was measured against the control. Control was prepared in the same way as described above, but water was taken instead of sample lysate.

4-HNE is considered as a marker for oxidative stress and is a well-known naturally occurring toxic by-product of lipid peroxidation. It was measured in a ninety-six-well format where samples (about $10 \mu \mathrm{g} / \mathrm{ml}$ ) were allowed to adsorb in the wells for $2 \mathrm{~h}$ at $37^{\circ} \mathrm{C}$. 4 -HNE protein adducts were then 
incubated with anti-HNE-His antibody, which was further incubated with horseradish peroxidase-conjugated secondary antibody. Initially, a standard curve was prepared with known concentrations of HNE-bovine serum albumin standards. 4-HNE contents in the treated/untreated skin tissues from the different groups of mice were measured as above and quantified using the HNE-bovine serum albumin standard curve.

Activity of GST was measured from $200 \mathrm{mg}$ of the treated/ untreated skin tissue lysates by documenting the increase in the absorbance of 1-chloro-2-4-dinitrobenzene (CDNB) as the substrate at $340 \mathrm{~nm}^{(14)}$. Specific activity of the enzyme is expressed as the formation of CDNB-glutathione (CDNBGSH) conjugate/min per $\mathrm{mg}$ protein. In brief, tissues were homogenised and centrifuged at $35000 \mathrm{~g}$ for $2 \mathrm{~h}$ at $4^{\circ} \mathrm{C}$. The supernatant was collected and incubated with $100 \mu \mathrm{l}$ CDNB in distilled water at $30^{\circ} \mathrm{C}$ for $5 \mathrm{~min}$. Then the reaction was initiated by the addition of $100 \mu \mathrm{l}$ GSH and optical density was taken at $340 \mathrm{~nm}$. Control was prepared as described above and distilled water was taken instead of tissue homogenate.

Activity of GPx was measured from $100 \mathrm{mg}$ of the treated/ untreated skin tissue lysates ${ }^{(15)}$. For the assay, NADPH and GR were mixed with the sample and the decrease in the absorbance of NADPH at $340 \mathrm{~nm}$ was immediately measured in the presence of $\mathrm{H}_{2} \mathrm{O}_{2}$. GPx activity is expressed as nmol of $\mathrm{NADPH}$ utilised/min per mg protein using the molar extinction coefficient of NADPH at $340 \mathrm{~nm}$ (6.22/nm per $\mathrm{cm})$.

CAT activity was also measured spectrophotometrically from $100 \mathrm{mg}$ of the skin tissue lysates ${ }^{(16)}$. Tissues were homogenised in phosphate buffer and centrifuged at $2500 \mathrm{~g}$ for $10 \mathrm{~min}$. The supernatant was used for the enzyme activity assay in the presence of $\mathrm{H}_{2} \mathrm{O}_{2}$ and measured spectrophotometrically at $240 \mathrm{~nm}$. The results are expressed as units/mg protein. The unit is defined as follows: one unit of CAT is the amount of enzyme that liberates half of the peroxide oxygen from $\mathrm{H}_{2} \mathrm{O}_{2}$ in $100 \mathrm{~s}$ at $25^{\circ} \mathrm{C}$.

SOD activity was measured from $200 \mathrm{mg}$ of the skin tissue lysates from the different groups of mice. Extraction and purification of SOD was performed according to the published protocol $^{(17)}$. SOD was quantified as an inhibition of pyrogallol auto-oxidation in Tris-HCl buffer ( $50 \mathrm{~mm}, \mathrm{pH} 7 \cdot 5)$, which was measured spectrophotometrically at $420 \mathrm{~nm}$, and the results are expressed as units/mg protein. The unit is defined as follows: one unit of enzyme activity is expressed as the amount of enzyme necessary for inhibiting the reaction by $50 \%$.

GSH activity was measured with the cytosolic fraction from $200 \mathrm{mg}$ of skin tissues obtained from the different groups of mice $^{(18)}$. The assay was designed to measure a decrease in dithiobis(2-nitro)-benzoic acid reduced by $-\mathrm{SH}$ groups and expressed as nmol/mg protein. First, a standard curve was prepared by measuring the absorbance of different known concentrations of GSH. The GSH enzyme activities from the treated/untreated skin samples were determined from the GSH standard curve.

GR is a flavoprotein catalysing the NADPH-dependent reduction of glutathione disulphide to GSH. GR activity was measured from $200 \mathrm{mg}$ of the skin tissue lysates obtained from the different groups of mice ${ }^{(19)}$. The oxidation of NADPH was measured spectrophotometrically at $340 \mathrm{~nm}$. Enzyme activity is expressed as nmol NADPH consumed/ min per mg protein based on the extinction coefficient of $\mathrm{NADPH}$, which is $6 \cdot 22 / \mathrm{nm}$ per $\mathrm{cm}$.

\section{Statistical analysis}

All the experiments were performed at least three times and were analysed and expressed as means and standard deviation. The data obtained from the 'untreated', 'acetone', 'DMBA' and 'DMBA + CARD' groups were statistically analysed by one-way ANOVA via Tukey's test, which is a pairwise comparison of the mean responses to the different treatment groups using Sigmastat statistical software (version 3) for Windows; Systat Software Inc.). $P<0.05$ was considered significant for all experiments.

\section{Results}

Morphological evidences of papillomas following the 7,12-dimethylbenz[a]anthracene and cardamom treatments

Female Swiss albino mice were grouped and treated as described in Table 1. The 'untreated', acetone- and 'DMBA'treated groups served as the normal control, vehicle control and carcinogen control, respectively. The effect of cardamom was determined in carcinogen-treated and cardamom-ingested mice designated as (DMBA + CARD). At the end of the 12th week, after the first topical DMBA application on mouse skin, the total incidences of papilloma growth were found to be reduced significantly both in number and sizes in the 'DMBA + CARD'-treated group with respect to the 'DMBA' group. No papillomas were observed in the 'untreated' and 'acetone' groups at any time point. A representative snapshot of mice from each group is shown in Fig. S1 of the supplementary material (available online at http://www.journals. cambridge.org/bjn). Cardamom-treated mouse skin did not show any papilloma growth on the skin at any time point (Fig. 1(b)).

\section{Effects of aqueous suspension of cardamom on the body weight and papilloma growth}

A normal growth pattern in body weights was observed in the 'untreated' and 'acetone'-treated groups throughout our experimental time points ( $0-12$ weeks). The body weights of the 'DMBA' group followed a much lower slope in growth pattern when compared with the other groups of mice (Fig. 1(a)). Growth pattern of the 'DMBA + CARD' group falls in between the growth rate of the 'DMBA' and 'acetone'/'untreated' groups. Papillomas started to appear on the DMBA-treated skin from the 5th week onwards and continued to grow until the end of the 12th week. Of these mice, $92 \%$ had papilloma growth due to the DMBA treatment on the shaved skin. Of the mice that received the aqueous 
(a)

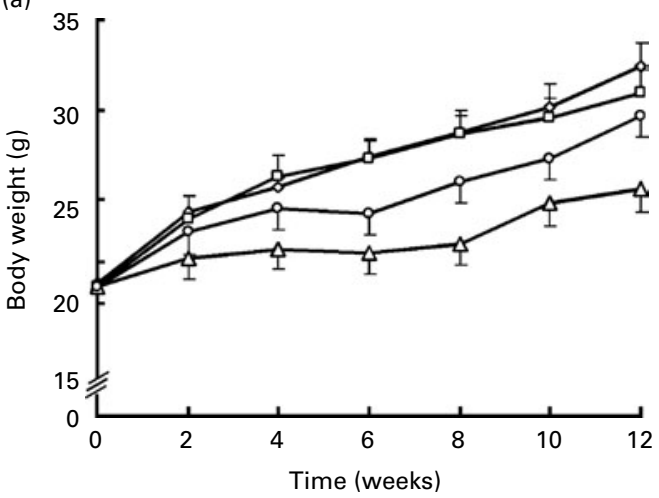

(b)

\begin{tabular}{l|rr|rc} 
Groups & $\begin{array}{r}\text { No. of papilloma } \\
\text { bearing mice }\end{array}$ & papilloma (\%) & No. of papilloma per mice \\
\hline Untreated & 0 (out of 24) & - & Mean & SD \\
Acetone & 0 (out of 24) & - & \multicolumn{2}{|c}{-} \\
DMBA & 22 (out of 24) & 92 & $6 \cdot 1$ & 1.72 \\
DMBA+ & 7 (out of 24) & 29 & 1.2 & 0.14 \\
CARD & & & & \\
CARD & 0 (out of 24) & - & \multicolumn{2}{|c}{-}
\end{tabular}

Fig. 1. Effects of topical application of 7,12-dimethylbenz[a]anthracene (DMBA) and ingestion of cardamom on body weight and papilloma growth. Swiss albino mice were grouped and treated as given in Table 1. (a) DMBA-treated mice (DMBA, $-\triangle$ ) demonstrated a significantly lower growth rate than that of DMBA-treated and cardamom-ingested mice (DMBA + CARD, $-0-$ ). The normal control (untreated, $\prec$ ) and acetone control (acetone, $-\square$ ) groups of mice showed a normal growth pattern. (B) Table describing the total incidences of papilloma growth on the skin in the experimental mice groups. Of the DMBA group, $92 \%$ had papilloma growth on their treated skin but the percentage dropped down to $29 \%$ for the DMBA + CARD group. The untreated, acetone-treated and CARD groups showed no papillomatous growth during the experimental period.

suspension of cardamom by oral administration after the first DMBA application, 29\% showed papilloma growth from the 7 th week instead of the 5 th week and showed regression in papilloma growth when compared with the DMBA group (Fig. 1(b)).

\section{Histology of the skin following induction of carcinogenesis and the cardamom treatment}

The histology of the skin from the 'DMBA' group demonstrated marked differences when compared with the 'acetone' group as described previously ${ }^{(12,20)}$. Severe hyperkeratosis and acanthosis were observed in DMBA-treated mouse skin, demonstrating progression towards skin carcinogenesis after 8 and 12 weeks (see Fig. S2(B and E) of the supplementary material, available online at http://www.journals.cambridge. org/bjn). 'Acetone'-treated mice demonstrated similar histology to that of the untreated mouse skin of the same age as shown previously ${ }^{(12)}$ (see Fig. S2(A and D) of the supplementary material, available online at http://www.journals. cambridge.org/bin). Histology of the affected skins from the 'DMBA + CARD' group demonstrated mild hyperkeratosis and moderate acanthosis of the epidermis, which revealed a near-normal morphology of the skin after 8 and 12 weeks (see Fig. S2(C and F) of the supplementary material, available online at http://www.journals.cambridge.org/bin).

\section{Effect of the aqueous suspension of cardamom on lipid peroxidation}

Lipid peroxidation is the unstable indicator of oxidative stress in cells that decompose to form more complex and reactive compounds such as MDA and 4-HNE. LPO are generated in the aerobic cells due to oxidative stress and the deleterious interaction of ROS with lipid molecules. These free radicals are produced in the body as normal consequences of biochemical processes and increased exposure to xenobiotics. Here we wanted to see whether aqueous suspension of cardamom has any effect on the DMBA-induced generation of LPO in the treated skins from the different groups of mice. We killed the different groups of mice at the end of 2, 8 and 12 weeks from the first dose of DMBA treatment. LPO values obtained from the 2nd and 8th week are given in Table S1 (available online at http://www.journals.cambridge.org/bin) and the LPO data obtained after 12th week are shown in Fig. 2. The DMBA treatment induced the formation of LPO in the mouse skin, which was significantly higher than that of the 'untreated' and 'acetone'-treated mouse skins. At the end of the 12 weeks, the generation of MDA and the production of 4-HNE were down-regulated to 5.25-fold $(P<0.001$; Fig. 2(a)) and 2.75 fold $(P<0.001 ;$ Fig. 2(b)), respectively, in the 'DMBA + CARD' group when compared with 'DMBA'-treated mice.

\section{Effect of the aqueous suspension of cardamom on host cellular defences}

Detoxification enzymes and antioxidants are the key players that maintain redox homeostasis of the cells and help in metabolism of the xenobiotics as a part of cellular defence system. Thus, we investigated the effects of cardamom (a)

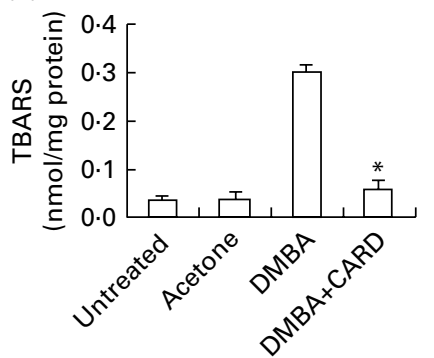

(b)

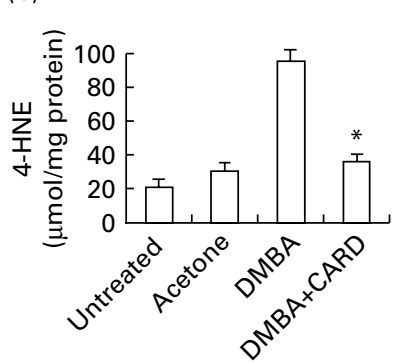

Fig. 2. Effects of ingestion of aqueous cardamom and 7,12-dimethylbenz [a]anthracene (DMBA) treatment on the generation of lipid peroxides (LPO) in treated skin tissue lysates after 12 weeks from first DMBA application. Malondialdehyde (MDA) and 4-hydroxynonenal (4-HNE) are the known toxic byproducts of LPO. Swiss albino mice were grouped and treated as given in Table 1. Treated/untreated skin tissue lysates from all the groups of mice were subjected to the (a) MDA assay and (b) 4-HNE assay to determine the levels of LPO among the samples. In both the cases, the DMBA + CARD group showed significantly reduced LPO $\left({ }^{*} P<0.001\right)$ when compared with DMBA-treated mice only. Values are means, with standard deviations represented by vertical bars. TBARS, thiobarbituric acid-reactive substance. CARD, cardamom ingested. 
ingestion against the development of skin papillomas initiated by DMBA on the activities of GST, GPx, GSH, GR, SOD and CAT. The treated/untreated skin tissue lysates obtained from the different groups of mice were used for the activity assays. Cardamom ingestion, following the DMBA treatments, elevated the activity levels of GST by $13 \cdot 1$-fold, combined GPx by $8 \cdot 62$-fold, GSH by $8 \cdot 17$-fold, GR by $16 \cdot 45$-fold, combined SOD by $22 \cdot 13$-fold and CAT by $13 \cdot 14$-fold when compared with DMBA-treated mice only. The increase in enzyme activities exceeded the basal levels of activities set by either 'untreated' or 'acetone'-treated mice in each case (Fig. 3).

\section{Cardamom rescues 7,12-dimethylbenz[a]anthracene-} induced down-regulation of nuclear factor erythroid-2related factor 2 and kelch-like $E C H$-associated protein 1 in mouse skin

$\mathrm{Nrf} 2$ is a basic region-leucine zipper transcription factor that regulates the induction of phase II detoxification enzymes during stress condition ${ }^{(21)}$. Keap1 is a cytoplasmic anchor for Nrf2 that tethers Nrf2 in the cytoplasm under basal unstressed conditions. Keap1 prevents Nrf2 from translocating to the nucleus, where it would bind to the antioxidant response element and activate gene transcription ${ }^{(22)}$. It has been reported that Nrf2 is released from Keap1 under oxidative stress, resulting in an enhanced nuclear accumulation and transcriptional induction of target genes (phase II detoxification enzymes) that ensure cell survival ${ }^{(23)}$. Immunohistochemistry (IHC) with Nrf2 and Keap1 on the untreated/treated skins from the different groups of mice is shown in Fig. $4(\mathrm{a}-\mathrm{c})$ (Nrf2) and Fig. 4(d-f) (Keap1) (one representative area from each group is shown). Skin tissue slides were stained with either Nrf2 or Keap1 antibody to evaluate the protein expression; the average expression of Nrf2 and Keap1 from each group of mice was quantified using the IHC pictographs, and analysed through Metamorph imaging software (Molecular Devices). The quantifications of the expressed proteins are represented as bar diagrams in Fig. 4(g) (Nrf2) and Fig. 4(h) (Keap1). It appeared that cardamom ingestion partially rescued the loss of expression of both Nrf2 and Keap1 due to the DMBA treatments.

\section{Cardamom restores the 7,12-dimethylbenz[a]anthracene- initiated activation of $N F-\kappa B$}

$\mathrm{NF}-\kappa \mathrm{B}$ is a transcription factor that has a crucial role in cell proliferation, inflammation, immunity and apoptosis ${ }^{(24)}$. During oxidative stress or UV radiation, activation of NF-кB mainly occurs via IкB kinase-mediated phosphorylation of inhibitory molecules, such as I $\mathrm{K} \mathrm{B} \alpha$. Once activated, IкB kinases phosphorylate $\mathrm{I} \kappa \mathrm{B} \alpha$ on Ser32 and Ser36 that lead towards ubiquitination and degradation of $\mathrm{I} \kappa \mathrm{B} \alpha$ via the ubiquitin proteasome pathway ${ }^{(25)}$. During stress conditions, NF-кB transcription factor subunit (p65) translocates into the (a)

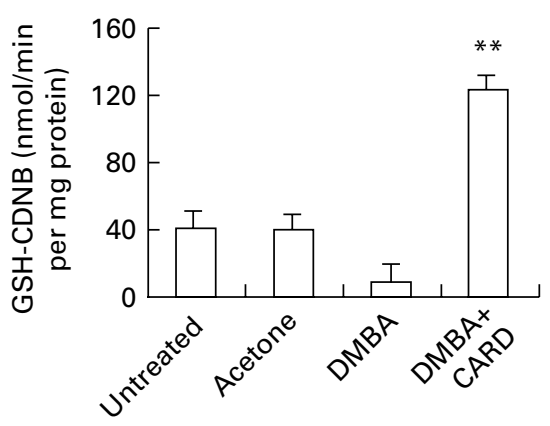

(d)

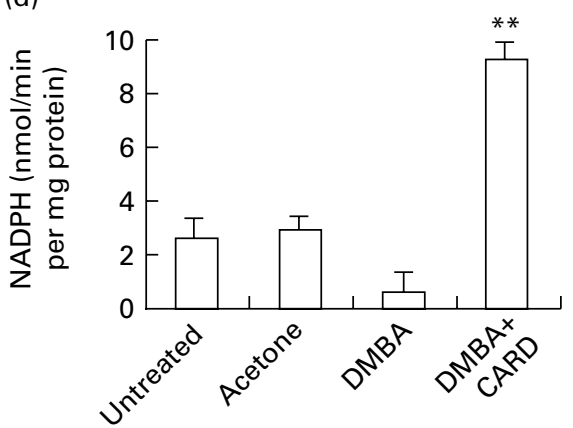

(b)

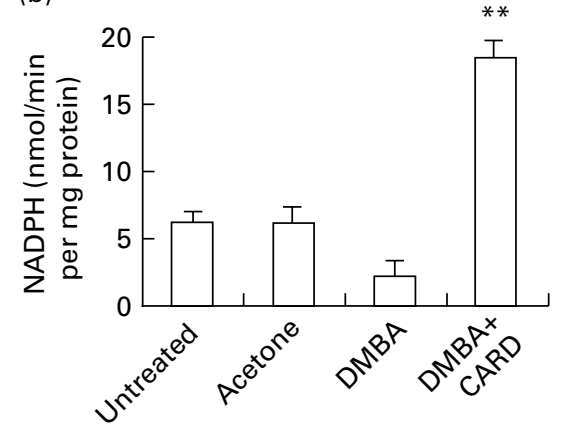

(e)

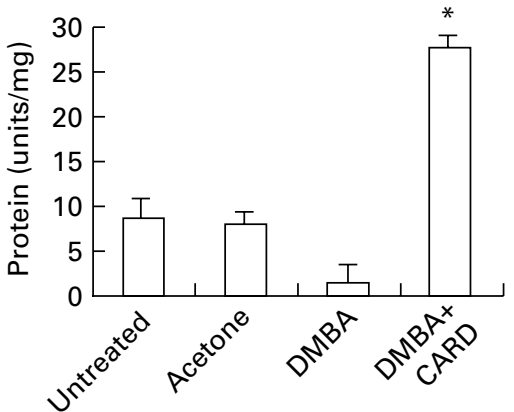

(c)

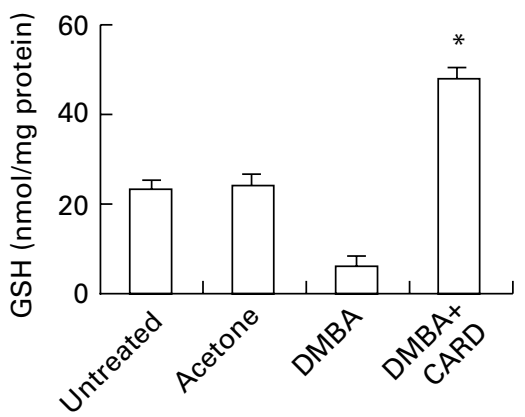

(f)

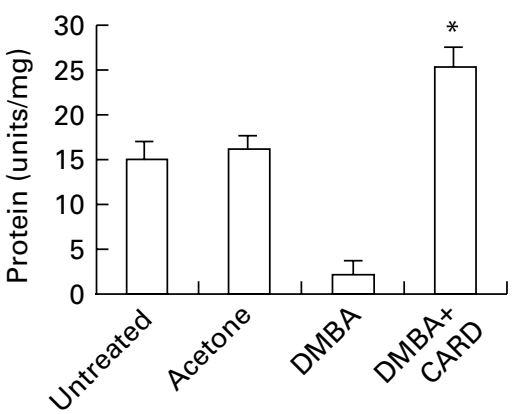

Fig. 3. Effects of ingestion of aqueous cardamom and 7,12-dimethylbenz[a]anthracene (DMBA) treatment on the activities of the detoxification enzymes in the treated/untreated skin tissue lysates obtained from the different groups of mice (Table 1) after 12 weeks from first DMBA application. The activities of (a) glutathione-S-transferase, (b) glutathione peroxidase, (c) reduced glutathione, (d) glutathione reductase, (e) superoxide dismutase and (f) catalase were significantly increased in the 'DMBA + CARD' group compared with the 'DMBA' group. The 'untreated' and 'acetone' groups demonstrate basal enzyme activities in each case. Values are means, with standard deviations represented by vertical bars. Mean value was significantly different from that of the DMBA group: ${ }^{\star} P<0.001,{ }^{\star *} P<0.005$. CARD, cardamom ingested. 
(a)

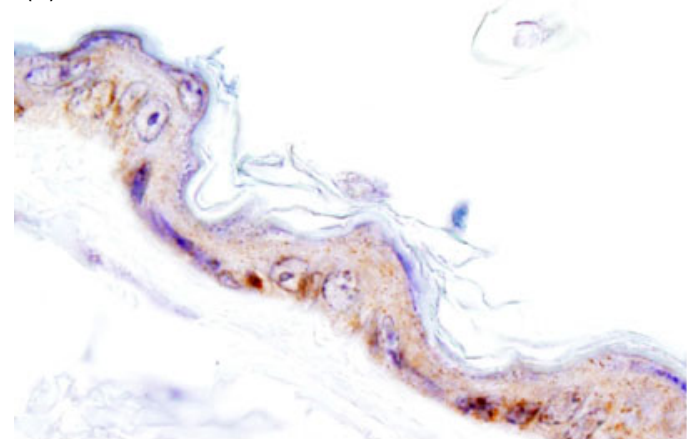

(b)
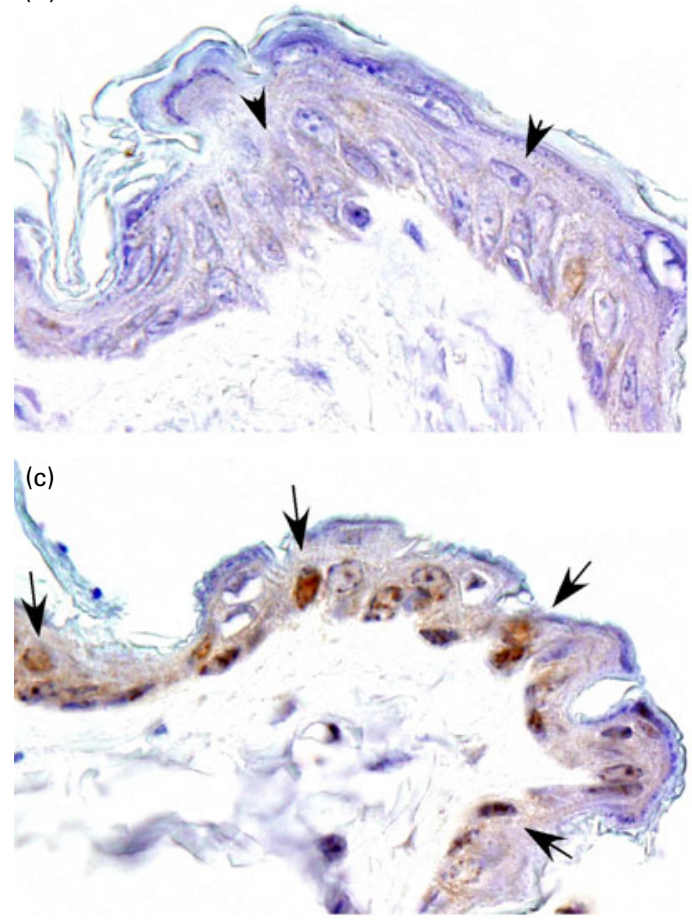

(g)

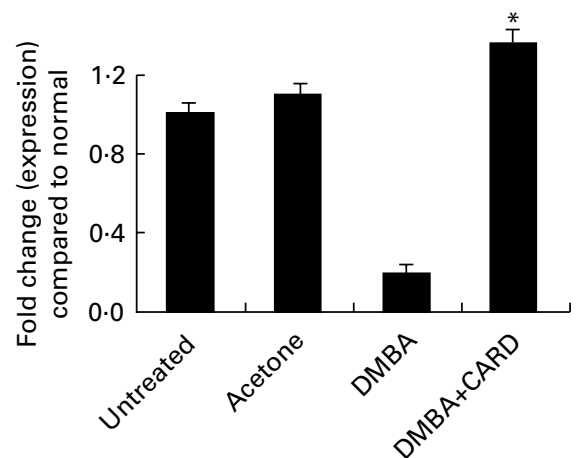

(d)

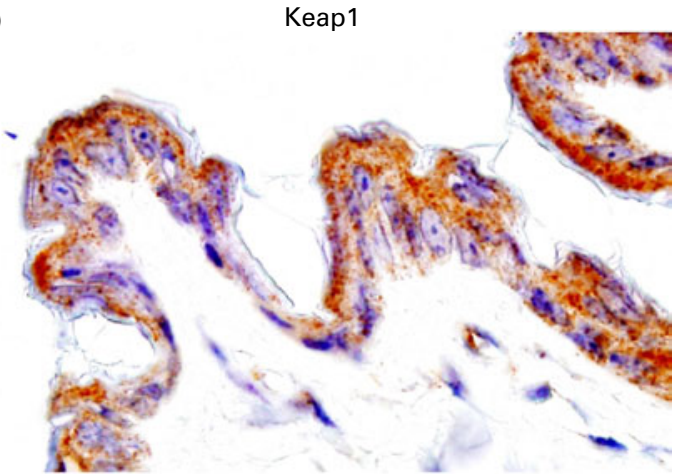

(e)

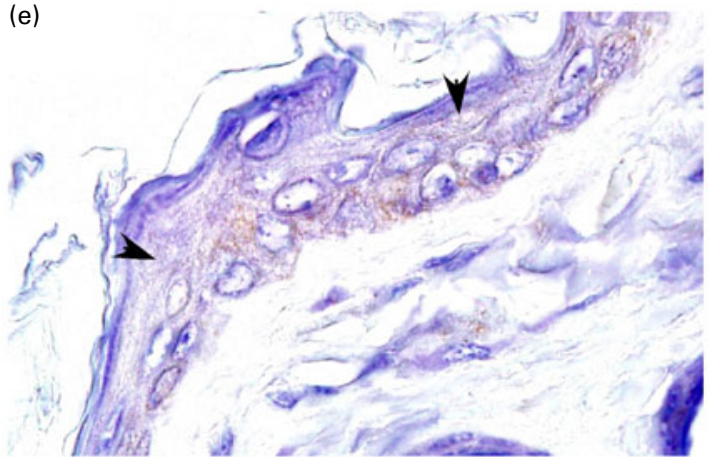

(f)

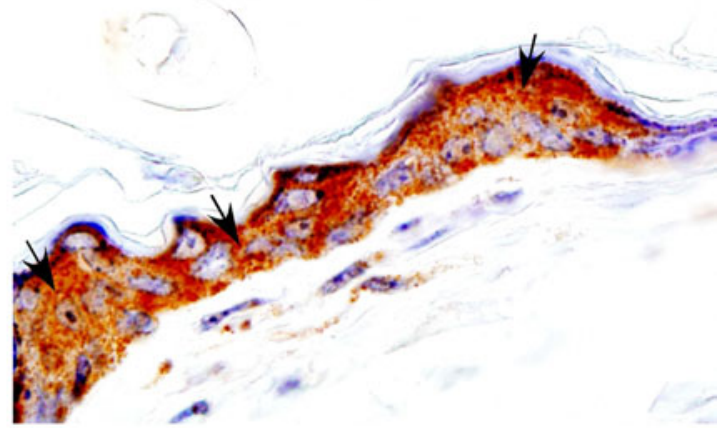

(h)

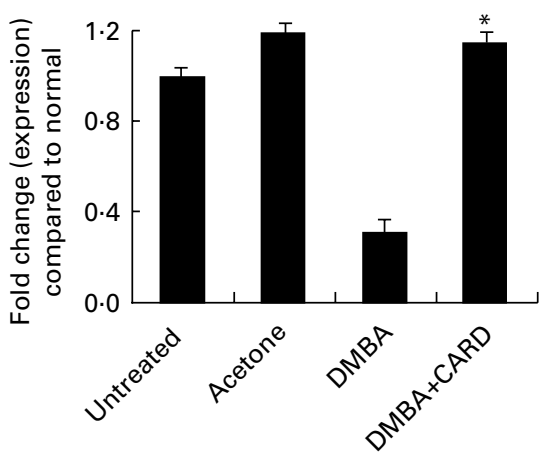

Fig. 4. Cardamom stimulates the expression of nuclear factor erythroid-2-related factor 2 (Nrf2) and kelch-like ECH-associated protein 1 (Keap1). Skin tissues from the different groups of mice (Table 1) were excised and tissue slides were prepared for immunohistochemistry (IHC). IHC with Nrf2 antibody was performed on the skin tissues obtained from (a) acetone-treated, (b) DMBA-treated and (c) DMBA + CARD-treated mice. Similarly, Keap1 antibody was also used to stain the skin tissues obtained from (d) acetone-treated, (e) DMBA-treated and (f) DMBA + CARD-treated mice. The magnifications of the pictographs are $200 \times$. Quantification of the expressions of $(\mathrm{g}) \mathrm{Nrf2}$ and $(\mathrm{h})$ Keap1 from several mouse skin tissues was evaluated using metamorph imaging software (Molecular Devices). Values are means, with standard deviations represented by vertical bars. * Mean value was significantly different from that of the DMBA group $(P<0.001)$. The arrowhead indicates loss of the expression; the arrows indicate gain in the expression. CARD, cardamom ingested. (A colour version of this figure can be found online at http://www.journals.cambridge.org/bjn). 

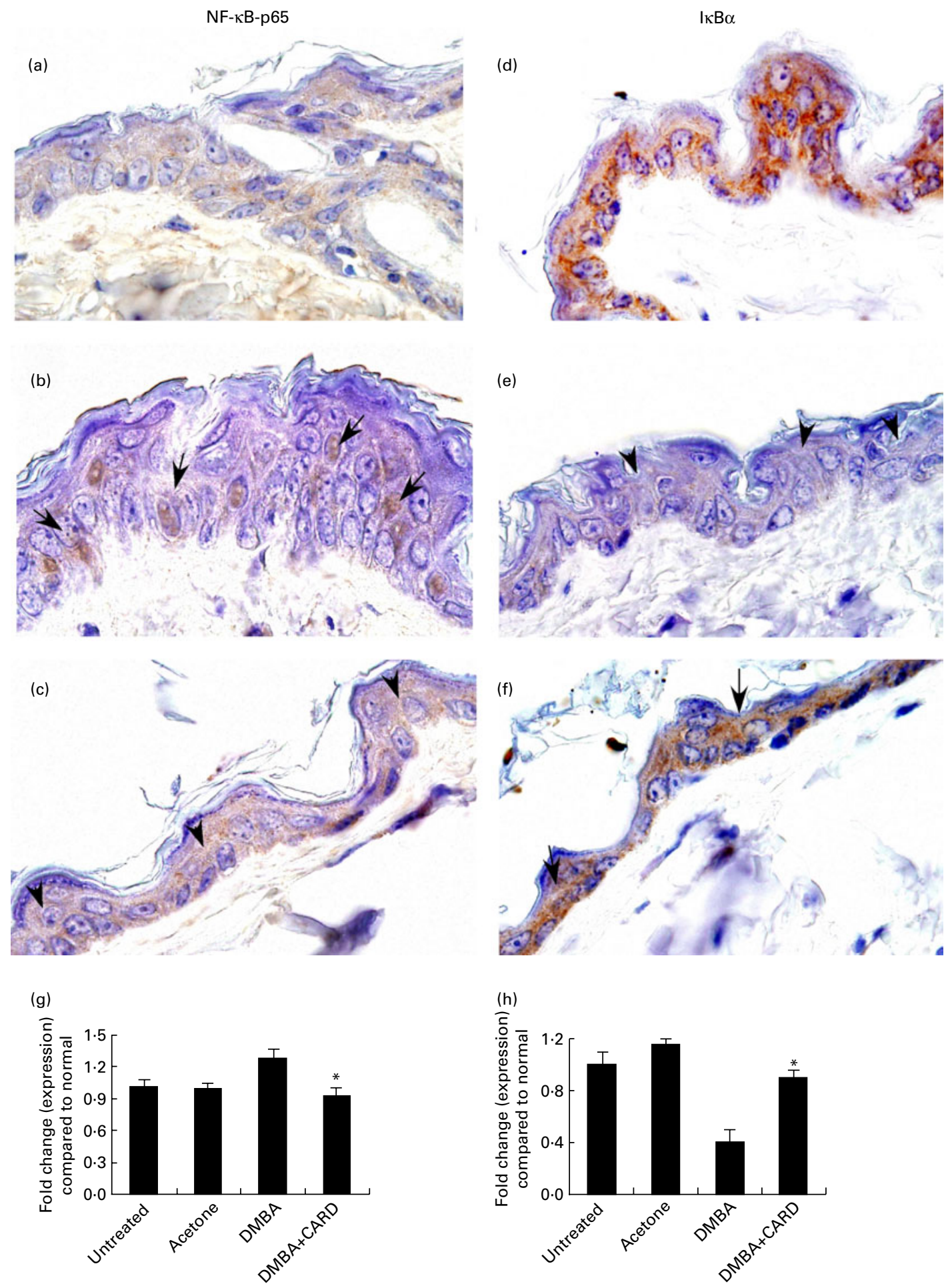

Fig. 5. Cardamom modulates the NF-кB signalling pathway. Different groups of mice were treated as described in Table 1. Skin tissues were excised and slides were prepared. Immunohistochemistry with NF-кB-p65 antibody was performed on the skin tissues obtained from (a) acetone-treated, (b) DMBA-treated and (c) DMBA + CARD-treated mice. Similarly, $1 \kappa B \alpha$ antibody was also used to stain the skin tissues obtained from (d) acetone-treated, (e) DMBA-treated and (f) DMBA + CARD-treated mice. The magnifications of the pictographs are $200 \times$. Quantification of the expressions of (g) NF-kB-p65 and (h) IkB $\alpha$ on skin tissues from several mice was evaluated using Metamorph Software (Molecular Devices). Values are means, with standard deviations represented by vertical bars. * Mean values were significantly different $(P<0.05)$. (h) * Mean value was significantly different form that of the DMBA group $(P<0.001)$. The arrowhead indicates loss of the expression; the arrows indicate gain in the expression. CARD, cardamom ingested. (A colour version of this figure can be found online at http://www.journals.cambridge.org/bjn). 
nucleus, where it binds to several regulatory proteins and regulates gene transcription. So, nuclear import is a key

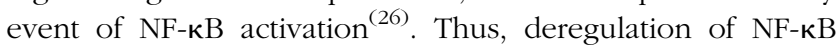
and $\mathrm{I} \kappa \mathrm{B} \alpha$ phosphorylation is crucial in inflammation and cancer $^{(3)}$, and it has become a popular target for therapeutic applications. IHC with NF-кB-p65 and IкB $\alpha$ on the treated/ untreated skins from the different groups of mice is shown

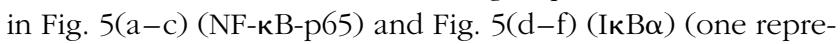
sentative area from each group is shown) to understand the impact of cardamom ingestion on the DMBA-treated mice in regulating $\mathrm{NF}-\kappa \mathrm{B}$ signalling. Several mouse skins from the different groups of mice were stained; the average staining intensities from each group of mice were quantified using IHC and analysed through Metamorph imaging software (Molecular Devices) and are represented as bar diagrams (Fig. 5(g), NF-кB-p65; Fig. 5(h), ІкB $\alpha$ ).

\section{Effect of cardamom on 7,12-dimethylbenz[a]anthracene- induced cyclo-oxygenase-2 expression}

Cyclo-oxygenase-2 (COX-2; an isoform of COX), an important inducible protein expressed during several carcinogenesis processes, is associated with PG synthesis, mitogenesis, apoptosis, angiogenesis and metastasis through various biological pathways ${ }^{(27)}$. COX-2 has been shown to express both in malignant epithelial cells and in neovasculature that continuously feed the tumour cells. Thus, COX-2 is considered as one of the markers of cancer progression and targeted inhibition of COX-2 is a promising approach to prevent skin cancer. Elevated level of COX-2 expression has been observed with $\mathrm{NMSC}^{(28)}$. The level of COX-2 expression in skin tissues was increased due to the DMBA treatment when compared with 'untreated' and 'acetone'-treated mice, which corroborates with the lines of evidence that tumour progression is associated with increased COX-2 expression (Fig. 6). COX-2 expression in the skin tissue obtained from the 'DMBA + CARD' group was reduced by $37 \%$ when compared with the DMBA-treated mouse skin only, demonstrating inhibition of neoplasia on the mouse skin by the aqueous ingestion of cardamom (Fig. 6).

\section{Discussion}

NMSC is the most frequent skin cancer in the USA with an incredible impact on physical condition and morbidity ${ }^{(1)}$. Although solar radiation is the leading cause of human skin cancer, it is also acknowledged that significant levels of chemical agents present in today's environment also contribute to growing incidences of cutaneous neoplasia in humans. In the area of cancer prevention, the use of natural phytoproducts and their constituents as potential chemopreventive agents remains a hot topic of intense research. In the present study, we have demonstrated the chemopreventive action of cardamom, which is a spice mostly used in Asian and Scandinavian cuisines, on DMBA-induced skin carcinogenesis in female Swiss albino mice. Phytochemicals that can metabolise or inhibit the formation of free radicals in vivo may be considered as potential anti-carcinogenic agents for cancer

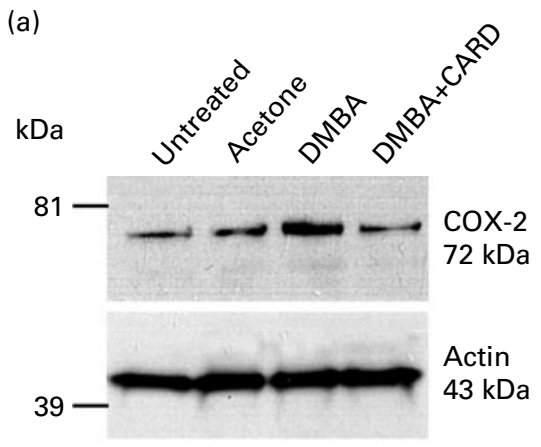

(b)

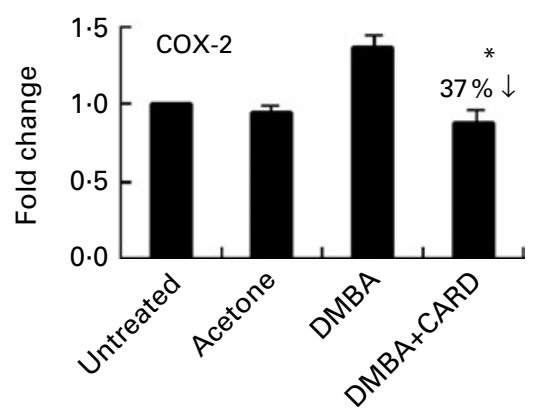

Fig. 6. Effects of ingestion of aqueous cardamom and 7,12-dimethylbenz [a]anthracene (DMBA) treatment on cyclo-oxygenase-2 (COX-2) expression. Swiss albino mice were grouped and treated as given in Table 1. COX-2 is a marker of carcinogenesis. (a) DMBA + CARD group showed reduced expressions of COX-2 when compared with the DMBA group as determined by Western blot. (b) Densitometry was performed with at least three different immunoblotting experiments. Percentage decrease in expression is indicated by the arrows. Values are means, with standard deviations represented by vertical bars. * Mean value was significantly different from that of the DMBA group $(P<0.01)$. CARD, cardamom ingested.

chemoprevention. In recent years, phytochemicals present in the common human diet have gained considerable attention as photoprotective and chemopreventive agents against skin cancers $^{(29)}$. These phytochemicals belong to numerous classes that include phytoalexins, phenols, polyphenols, anthocyanidins flavonoids, isoflavonoids and carotenoids. The chemopreventive approach appears to have realistic implications in inhibiting skin cancer in individuals because of their ability to modify dietary intake and change in the lifestyle.

There are several dietary phytochemicals that demonstrate an immense effect on chemically induced skin carcinogenesis. Oral administration of epigallocatechin gallate, which is a polyphenol, blocked the growth of UV-induced skin tumours in mice, by decreasing $\mathrm{H}_{2} \mathrm{O}_{2}$-induced ROS and reducing inducible NO synthase expression in the UV-irradiated skin ${ }^{(30)}$ Pretreatment with genistein, an isoflavone, to hairless mice before UV exposure considerably blocked the UV-induced $\mathrm{H}_{2} \mathrm{O}_{2}$ and MDA formation in the skin, as well as minimised the generation of 8-hydroxy-2'-deoxyguanosine in the epidermis ${ }^{(31)}$. In SENCAR mice, topical application of genistein before UVB radiation reduced c-fos and c-jun expression ${ }^{(32)}$ that are linked with cancer progression. Resveratrol is a polyphenol phytoalexin, and topical application of resveratrol before UVB irradiation to SKH-1 hairless mice resulted in considerable inhibition of UV-induced skin oedema as well as 
inhibition of the formation of $\mathrm{H}_{2} \mathrm{O}_{2}^{(33)}$. Resveratrol treatment to mouse skin also significantly inhibited the induction of COX-2 and lipid peroxidation, as well as repressed UVB-mediated activation of the NF- $\kappa$ B pathway ${ }^{(34)}$. Silymarin, which is a polyphenol flavonoid, promotes the reduction of UVA-caused oxidative stress by reducing GSH depletion, blocking ROS and LPO production, as well as deactivating NF-кB activation in irradiated cells. Moreover, topical application of silymarin protects SKH-1 hairless mice against tumour initiation either with UVB or DMBA, stimulates CAT activity and inhibits COX-2 expression $^{(35)}$. Topical application of another well-known phytochemical, curcumin, also inhibited COX-2 expression by suppressing p38 and c-Jun N-terminal kinase activities in HaCaT cells ${ }^{(36)}$. Gingerol, on the other hand, repressed the UVB-induced intracellular ROS levels, inhibited the activation of caspase-3, -8, -9 and TNF receptor superfamily, member 6 (Fas) expression, down-regulated COX-2 expression and NF$\kappa \mathrm{B}$ activation ${ }^{(37)}$. Moreover, delphinidin, a dietary anthocyanidin, protected cells against UVB-mediated decrease in cell viability, as well as down-regulated the levels of lipid peroxidation and blocked DNA damage. Application of lycopene, which is found in tomatoes, inhibited UVB-induced ornithine decarboxylase and proliferating cell nuclear antigen inhibition, downregulated myeloperoxidase activities and significantly reduced bifold skin thickness ${ }^{(38)}$. Thus, several individual components show excellent promise to protect cells against the propagation of skin carcinogenesis. Researchers are now interested in the combinatorial effects of several phytochemicals against chemically induced skin carcinogenesis. Recently, Kowalczyk et $a{ }^{(39)}$ demonstrated the inhibitory effect of combined phytochemicals on DMBA-induced murine skin tumorigenesis and obtained a significantly higher efficacy than individual compounds.

DMBA is a well-known carcinogen and often used with croton oil or 12-O-tetradecanoylphorbol-13-acetate (TPA) to generate experimental papillomas on the skin. TPA and croton oil have been used for ages to initiate the two-stage skin carcinogenesis in mice ${ }^{(39-43)}$. The use of DMBA with TPA or croton oil generates ROS, promotes DNA damage, modulates p53 and COX-2 function, deregulates the cell cycle and also alters apoptosis in the $\operatorname{skin}^{(12,20,44,45)}$. Thus, our system of generating experimental skin papilloma in mice by croton oil and DMBA somewhat mimics NMSC in humans. ROS also induces peroxidation of PUFA and causes lipid peroxidation in the cellular membrane. Increased lipid peroxidation has been found to be triggered due to amplified arachidonic acid metabolism via increased activities of cyclooxygenases, such as COX-1 and COX-2, to produce PG ${ }^{(46)}$. MDA and 4HNE, the toxic by-products of lipid peroxidation formed during PG biosynthesis, are mutagenic and genotoxic that can promote cancer growth. Oral administration of aqueous cardamom to DMBA-treated mice showed significantly inhibited lipid peroxidation (Fig. 2), as well as demonstrated a decrease in the expression of COX-2 (Fig. 6), indicating beneficial functions of cardamom.

Cardamom extracts were also tested on the activities of phase II detoxification enzymes and antioxidation enzymes. GST and GPx play a vital role in inducing the detoxification of foreign compounds in the body to non-toxic and easily soluble components that can be easily excreted from the system. On the other hand, GR catalyses the conversion of glutathione disulphide to GSH for a fresh round of detoxification action. The antioxidation enzymes, particularly CAT and SOD, also provide protection to cells against ROS by detoxifying them on the site where they are produced. SOD and CAT are regarded as the first line of antioxidant defence that protect cells against oxidative stress. SOD neutralises the $\mathrm{O}_{2}^{-}$ anion to $\mathrm{H}_{2} \mathrm{O}_{2}$ and $\mathrm{O}_{2}$, whereas CAT neutralises $\mathrm{H}_{2} \mathrm{O}_{2}$ to $\mathrm{O}_{2}$ and water $^{(12)}$. Hence, the significant enhancement of the level of activities of GST, GPx, GSH, GR, SOD and CAT in the 'DMBA + CARD' group (Fig. 3) may be beneficial for inhibiting the incidences of papilloma generation due to DMBA application on mouse skin. Cardamom ingestion by DMBAtreated mice even elevated the levels of the enzyme activities beyond the basal levels of the 'untreated' and 'acetone'-treated groups. Thus, it indicates that intake of whole cardamom every day in the normal diet has an enormous potential to boost the cellular defence system of the body that will be more appropriate to combat different stress conditions.

To understand the mechanism, we have investigated the molecular function of cardamom on Nrf2 and NF- $\mathrm{\kappa B}$ transcription factors. The present data indicate that there is a loss of expression of $\mathrm{Nrf} 2$ (Fig. 4(b and g)) as well as Keap1 (Fig. 4(e and h)) in the 'DMBA'-treated skin when compared with the 'acetone'-treated skins (Fig. 4(a), Nrf2; Fig. 4(d), Keap1). 'Acetone'-treated mouse skin expresses Nrf2 in the cytoplasmic region, which closely resembles the expression of Nrf2 on the skin of 'untreated' mice (compare Fig. 4(a) and Fig. S3(A) of the supplementary material, available online at http://www.journals.cambridge.org/bjn). Interestingly, cardamom ingestion rescues the nuclear expression of $\mathrm{Nrf} 2$ in the mouse skin of the 'DMBA + CARD' group, which suggests that the cardamom treatment might trigger an activation of Nrf2 despite the deleterious effects of DMBA, to maintain cellular homeostasis during oxidative stress (Fig. 4(c and g)). Nrf2 transcription factor is well known for leading the induction of phase II detoxification enzymes during oxidative stress, and we have already demonstrated an induction of several phase II detoxification enzymes due to the cardamom treatments in 'DMBA + CARD' mice (Fig. 3). Moreover, Keap1 is highly expressed in the cytoplasm of the 'untreated' and 'acetone'-treated mouse skin (Fig. 4(d) and Fig. S3(B) of the supplementary material, available online at http://www. journals.cambridge.org/bjn). Loss of Keap1 in the 'DMBA'treated skin is restored by cardamom intake, suggesting a reversion of DMBA-associated malfunction in the skin (Fig. 4(f and h)). Although an association between Keap1 and Nrf2 is required by the resting cells, our experimental observations with these two proteins may not be linked to each other in the present scenario. Keap1 has often been found to be expressed in low levels and mutated in patients with cancer ${ }^{(47)}$. Low expression of Keap1 is probably due to the epigenetic silencing via Keap1 promoter methylation ${ }^{(48)}$.

Furthermore, nuclear expression of NF-кB-p65 has been observed in 30-40\% of the epidermal cells in the 'DMBA'-treated skin (Fig. 5(b and g)) when compared 
with the 'untreated' and 'acetone'-treated skins (see Fig. S3(C) of the supplementary material, available online at http://www. journals.cambridge.org/bjn and Fig. 5(a and g)). This observation suggests an activation of the NF- $\mathrm{KB}$ signalling cascade in carcinogen-treated mice, by facilitating the release of NF$\kappa \mathrm{B}-\mathrm{p} 65$ protein from its cytoplasmic inhibitor protein, IкB $\alpha$. Additionally, IHC with $\mathrm{I} \kappa \mathrm{B} \alpha$ displayed down-regulation of I $\mathrm{B} \alpha$ expression in the skins of DMBA-treated mice, suggesting that the ability to sequester NF-кB-p65 protein in the cytoplasm was lost (Fig. 5(e and g)). The cardamom treatment restored the expression of NF-кB-p65 protein in the cytoplasm regardless of the deleterious effects of DMBA on the skin (Fig. 5(c and g)). It is possibly due to simultaneous up-regulation of the inhibitory protein $\mathrm{I} \kappa \mathrm{B} \alpha$ in the cytoplasm (Fig. 5(f and h)) that resembles the resting phase in 'untreated' or 'acetone'-treated mice (see Fig. S3(D) of the supplementary material, available online at http://www.journals.cambridge. org/bjn and Fig. 5(d and h)). We observed subtle differences in the expression levels in NF-кB-p65 or ІкB $\alpha$ between the 'untreated' and 'acetone'-treated groups that may be due to the variation in the animal pool. There are multiple lines of evidence supporting the hypothesis that the induction of COX-2 is regulated by NF- $\kappa \mathrm{B}^{(49)}$. Activation of NF- $\kappa \mathrm{B}$ occurred due to DMBA application on the mouse skin, and thus there might be an increase in COX-2 expression. Additionally, both SOD and COX-2 expressions are partly regulated by $\mathrm{NF}-\kappa \mathrm{B}$. So it is likely that cardamom modulates the NF- $\mathrm{B}$ signalling and induces the expression of SOD to inhibit the translocation of NF-кB-p65 to the nucleus and concurrently block NF- $\mathrm{B}$ activation.

In general, NF- $\mathrm{B}$ activation is often linked with increased survival of the tumour cells and resistance to chemotherapy. Several anti-carcinogenic compounds that could act as potential inhibitors of NF- $\mathrm{kB}$ activity are in the process of development for an anticancer therapy ${ }^{(50)}$. However, activation of NF$\kappa \mathrm{B}$ can also sensitise cells to apoptosis ${ }^{(51)}$. For example, a combination of both UV radiation and adriamycin treatment can activate the NF- $\mathrm{kB}$ signalling pathway, which in turn inhibits the expression of a couple of anti-apoptotic genes. Induction of anti-apoptotic proteins by activating NF- $\mathrm{B}$ might be one of the many possible ways that is required for the development of skin carcinogenesis ${ }^{(52)}$. Activation of NF- $\mathrm{KB}$ has been convincingly shown to promote melanoma progression $^{(53,54)}$. Furthermore, in dysplastic nevi and melanoma lesions, NF-кB activity was found to be highly up-regulated when compared with the normal human nevi or melanocytes $^{(54,55)}$. Thus, expression of any proteins or agent/s that could potentially deactivate NF- $\mathrm{B}$ would be of high interest in the therapy against skin carcinogenesis. For example, in keratinocytes, expression of mutant JUN leads to the downregulation of $\mathrm{NF}-\kappa \mathrm{B}$ and that eventually suppresses the tumour phenotype ${ }^{(56)}$. In contrast, it has also been reported that mice with down-regulated NF-кB function display features of squamous cell carcinoma ${ }^{(57)}$. Similar effects have been shown by using lupeol, an anticarcinogenic compound, on TPA-induced skin papillomatogenesis in CD1 mice. Lupeol treatment helps in the reduction of skin oedema/hyperplasia, and it is associated with the decrease in the expression/activity of COX-2, NO synthase and epidermal ornithine decarboxylase. Additionally, a decrease in the activation of phosphatidylinositol 3-kinase (PI3K) and NF- $\mathrm{KB}$ signalling, as well as a decrease in the degradation of $\mathrm{I} \kappa \mathrm{B} \alpha$, was observed in lupeol-treated mice ${ }^{(58)}$. Another group also showed that skin papillomas generated in DMBA/TPA in LACA mice were associated with increased expression of NF- $\mathrm{B}$ and activator protein 1 (AP1). Inhibition of papillomatosis by Azadirachta indica (a leaf extract) was accompanied by the induction of signal transduces and activator of transcription 1/AP1 and simultaneously knocked down the activity of NF- $\mathrm{BB}^{(59)}$.

In the present study, we have also shown the histology of mouse skin obtained from different groups of mice. Histology of the skin from the 'DMBA + CARD'-treated group showed a near-normal phenotype similar to either the 'acetone' or 'untreated' group (no squamous cell carcinoma characteristics), which was remarkably different from the 'DMBA'-treated group (Fig. S2 of the supplementary material, available online at http://www.journals.cambridge.org/bjn). Extrapolating these facts, we can state that cardamom might also have an impact on the function and expression of TNF$\alpha$. NF- $\mathrm{B}$ activation also facilitates COX-2 expression. We have showed that cardamom ingestion in DMBA-treated mice shows down-regulation of COX-2, and could potentially also down-regulate NO synthase and epidermal ornithine decarboxylase. Moreover, cardamom might also modulate the PI3K and AP1 signalling pathways to restore the normal cellular homeostasis of the papilloma-bearing cells.

It is well known that squamous cell carcinoma, which are responsible for the majority of NMSC-related deaths, result from the accumulation of genetic alterations. Several molecular events occur in skin epidermal cells following UV exposure such DNA damage, generation of ROS, induction of p53 and p53-regulated proteins, cell-cycle arrest, DNA repair and apoptosis. Natural phytoproducts, such as cardamom, with antitumorigenic properties have an immense potential to maintain cellular homeostasis when continuously taken as dietary supplements. There are several active components of cardamom and not all the components are examined separately. Several reports have demonstrated that most of the components of cardamom act as antioxidants such as limonene, cineole, linalool, pinene and borneol ${ }^{(9)}$. Cardamom contains $\mathrm{Cu}$ and $\mathrm{Mn}$ that are required for the activation of SOD enzyme, which in turn helps in the decrease in the process of lipid peroxidation. So in conclusion, generation of DMBA-induced skin papillomatogenesis most probably mimics UV-induced NMSC in humans, and the present data suggest that whole cardamom as a nutritional diet plays an anti-carcinogenic role in preventing the progression of skin carcinogenesis in mice. Further investigations with individual components are required to establish the chemopreventive role of cardamom against NMSC.

\section{Acknowledgements}

I. D. wishes to thank the Director, Jaydeep Biswas, and all the other staff members of the Department of Cancer Chemoprevention, CNCI. T. S. thanks the Lombardi Comprehensive 
Cancer Center, Histopathology core and acknowledges the support from the pilot grants from the American Cancer Society (IRG no. 97-152-16-2) and the Fisher Center for Familial Cancer Center, Georgetown University (Washington, DC, USA). The authors' contributions are as follows: I. D. designed and performed the experiments (mouse set-up, tissue preparation, biochemical and immunohistochemical assays) as well as assisted in organising the manuscript; A. A. performed the experiments (immunoblotting with the tissue lysates) and reviewed the writing of the manuscript. D. L. B., S. S., E. W. and E. P. were involved in tissue handing, slide preparation, haematoxylin and eosin and IHC staining of the skin slides in the USA. A. S. and S. B. provided space and reagents in India. T. S. supervised the research, designed the experiments, provided the reagents, space and scholarly wrote the manuscript. The authors declare that they have no conflict of interest.

\section{References}

1. National Cancer Institute Skin Cancer (2011) http:// wwwcancergov/cancertopics/types/skin (accessed 22 September 2011)

2. Ramos J, Villa J, Ruiz A, et al. (2004) UV dose determines key characteristics of nonmelanoma skin cancer. Cancer Epidemiol Biomarkers Prev 13, 2006-2011.

3. Acharya A, Das I, Chandhok D, et al. (2010) Redox regulation in cancer: a double-edged sword with therapeutic potential. Oxid Med Cell Longev 3, 23-34.

4. Sander CS, Hamm F, Elsner P, et al. (2003) Oxidative stress in malignant melanoma and non-melanoma skin cancer. $\mathrm{Br} J$ Dermatol 148, 913-922.

5. Sporn MB, Dunlop NM, Newton DL, et al. (1976) Prevention of chemical carcinogenesis by vitamin A and its synthetic analogs (retinoids). Fed Proc 35, 1332-1338.

6. Tapsell LC, Hemphill I, Cobiac L, et al. (2006) Health benefits of herbs and spices: the past, the present, the future. Med J Aust 185, S4-24.

7. Wikipedia TFE (2011) Cardamom. Wikimedia Foundation, Inc. (cited 16 September 2011)

8. Zachariah TJ Chemistry of cardamom. In Cardamom, The Genus Elettaria [PM Ravindran and KJ Madhusoodanan, editors]. London: Taylor and Francis.

9. Acharya A, Das I, Singh S, et al. (2010) Chemopreventive properties of indole-3-carbinol, diindolylmethane and other constituents of cardamom against carcinogenesis. Recent Pat Food Nutr Agric 2, 166-177.

10. Huang YB, Fang JY, Hung CH, et al. (1999) Cyclic monoterpene extract from cardamom oil as a skin permeation enhancer for indomethacin: in vitro and in vivo studies. Biol Pharm Bull 22, 642-646.

11. Bhattacharjee S, Rana T \& Sengupta A (2007) Inhibition of lipid peroxidation and enhancement of GST activity by cardamom and cinnamon during chemically induced colon carcinogenesis in Swiss albino mice. Asian Pac J Cancer Prev $\mathbf{8}$, $578-582$.

12. Das I \& Saha T (2009) Effect of garlic on lipid peroxidation and antioxidation enzymes in DMBA-induced skin carcinoma. Nutrition 25, 459-471.

13. Ando S, Kon K, Aino K, et al. (1990) Increased levels of lipid peroxides in aged rat brain as revealed by direct assay of peroxide values. Neurosci Lett 113, 199-204.
14. Habig WH, Pabst MJ \& Jakoby WB (1974) Glutathione $S$-transferases. The first enzymatic step in mercapturic acid formation. J Biol Chem 249, 7130-7139.

15. Paglia DE \& Valentine WN (1967) Studies on the quantitative and qualitative characterization of erythrocyte glutathione peroxidase. J Lab Clin Med 70, 158-169.

16. Luck H (1963) A spectrophotometric method for the measurement of catalase. Meth Enzymatic Anal 27, $885-895$.

17. Marklund S \& Marklund G (1974) Involvement of the superoxide anion radical in the autoxidation of pyrogallol and a convenient assay for superoxide dismutase. Eur J Biochem 47, 469-474.

18. Sedlak J \& Lindsay RH (1968) Estimation of total, proteinbound, and nonprotein sulfhydryl groups in tissue with Ellman's reagent. Anal Biochem 25, 192-205.

19. Carberg I \& Mannervick B (1985) Glutathione reductase. In Methods in Enzymology [S Fleisher and L Packer, editors]. New York, NY: Academic Press.

20. Das I, Das S \& Saha T (2009) Saffron suppresses oxidative stress in DMBA-induced skin carcinoma: a histopathological study. Acta Histochem 26, 26.

21. Cho HY, Reddy SP, Debiase A, et al. (2005) Gene expression profiling of NRF2-mediated protection against oxidative injury. Free Radic Biol Med 38, 325-343.

22. Kensler TW \& Wakabayashi N (2009) Nrf2: friend or foe for chemoprevention? Carcinogenesis 30, 30.

23. Motohashi H \& Yamamoto M (2004) Nrf2-Keap1 defines a physiologically important stress response mechanism. Trends Mol Med 10, 549-557.

24. Baud V \& Karin M (2009) Is NF-kappaB a good target for cancer therapy? Hopes and pitfalls. Nat Rev Drug Discov $\mathbf{8}$, $33-40$.

25. Zandi E, Rothwarf DM, Delhase M, et al. (1997) The IkappaB kinase complex (IKK) contains two kinase subunits, IKKalpha and IKKbeta, necessary for IkappaB phosphorylation and NF-kappaB activation. Cell 91, 243-252.

26. Sochanowicz B, Szumiel I \& Gradzka I (1999) Nuclear translocation of the p65 subunit of NF-kappaB in L5178Y sublines differing in antioxidant defense. Radiat Environ Biophys 38, 125-131.

27. Miglietta A, Toselli M, Ravarino N, et al. (2010) COX-2 expression in human breast carcinomas: correlation with clinicopathological features and prognostic molecular markers. Expert Opin Ther Targets 14, 655-664.

28. An KP, Athar M, Tang X, et al. (2002) Cyclooxygenase-2 expression in murine and human nonmelanoma skin cancers: implications for therapeutic approaches. Photochem Photobiol 76, 73-80.

29. Surh YJ (2003) Cancer chemoprevention with dietary phytochemicals. Nat Rev Cancer 3, 768-780.

30. Katiyar SK \& Mukhtar H (2001) Green tea polyphenol (-)epigallocatechin-3-gallate treatment to mouse skin prevents UVB-induced infiltration of leukocytes, depletion of antigen-presenting cells, and oxidative stress. J Leukoc Biol 69 , $719-726$.

31. Wei H, Zhang X, Wang Y, et al. (2002) Inhibition of ultraviolet light-induced oxidative events in the skin and internal organs of hairless mice by isoflavone genistein. Cancer Lett 185, 21-29.

32. Wang $\mathrm{Y}$, Zhang $\mathrm{X}$, Lebwohl $\mathrm{M}$, et al. (1998) Inhibition of ultraviolet B (UVB)-induced c-fos and c-jun expression in vivo by a tyrosine kinase inhibitor genistein. Carcinogenesis 19, 649-654. 
33. Afaq F, Adhami VM \& Ahmad N (2003) Prevention of shortterm ultraviolet $\mathrm{B}$ radiation-mediated damages by resveratrol in SKH-1 hairless mice. Toxicol Appl Pharmacol 186, 28-37.

34. Adhami VM, Afaq F \& Ahmad N (2003) Suppression of ultraviolet B exposure-mediated activation of NF-kappaB in normal human keratinocytes by resveratrol. Neoplasia 5, $74-82$.

35. Katiyar SK, Korman NJ, Mukhtar H, et al. (1997) Protective effects of silymarin against photocarcinogenesis in a mouse skin model. J Natl Cancer Inst 89, 556-566.

36. Cho JW, Park K, Kweon GR, et al. (2005) Curcumin inhibits the expression of COX-2 in UVB-irradiated human keratinocytes (HaCaT) by inhibiting activation of AP-1: p38 MAP kinase and JNK as potential upstream targets. Exp Mol Med 37, 186-192.

37. Kim JK, Kim Y, Na KM, et al. (2007) [6]-Gingerol prevents UVB-induced ROS production and COX-2 expression in vitro and in vivo. Free Radic Res 41, 603-614.

38. Fazekas Z, Gao D, Saladi RN, et al. (2003) Protective effects of lycopene against ultraviolet B-induced photodamage. Nutr Cancer 47, 181-187.

39. Kowalczyk MC, Kowalczyk P, Tolstykh O, et al. (2010) Synergistic effects of combined phytochemicals and skin cancer prevention in SENCAR mice. Cancer Prev Res 3, $170-178$.

40. Bowden GT, Schneider B, Domann R, et al. (1994) Oncogene activation and tumor suppressor gene inactivation during multistage mouse skin carcinogenesis. Cancer Res 54, 1882s-1885s.

41. Kapadia GJ, Azuine MA, Sridhar R, et al. (2003) Chemoprevention of DMBA-induced UV-B promoted, NOR-1-induced TPA promoted skin carcinogenesis, and DEN-induced phenobarbital promoted liver tumors in mice by extract of beetroot. Pharmacol Res 47, 141-148.

42. Kim MO, Kim SH, Shin MJ, et al. (2007) DMBA/TPA-induced tumor formation is aggravated in human papillomavirus type 16 E6/E7 transgenic mouse skin. Oncol Res 16, 325-332.

43. Schneider BL, Bowden GT, Sutter C, et al. (1993) 7,12Dimethylbenz[a]anthracene-induced mouse keratinocyte malignant transformation independent of Harvey ras activation. J Invest Dermatol 101, 595-599.

44. Bhattacharyya SS, Paul S, Mandal SK, et al. (2009) A synthetic coumarin (4-methyl-7 hydroxy coumarin) has anti-cancer potentials against DMBA-induced skin cancer in mice. Eur J Pharmacol 614, 128-136.

45. Chaudhary SC, Alam MS, Siddiqui MS, et al. (2009) Chemopreventive effect of farnesol on DMBA/TPA-induced skin tumorigenesis: involvement of inflammation. Ras-ERK pathway and apoptosis. Life Sci 85, 196-205.
46. Bartsch H \& Nair J (2005) Accumulation of lipid peroxidation-derived DNA lesions: potential lead markers for chemoprevention of inflammation-driven malignancies. Mutat Res 591, 34-44.

47. Hayes JD \& McMahon M (2009) NRF2 and KEAP1 mutations: permanent activation of an adaptive response in cancer. Trends Biochem Sci 34, 176-188.

48. Wang R, An J, Ji F, et al. (2008) Hypermethylation of the Keap1 gene in human lung cancer cell lines and lung cancer tissues. Biochem Biophys Res Commun 373, 151-154.

49. Ulivi V, Giannoni P, Gentili C, et al. (2008) p38/NF-kBdependent expression of COX-2 during differentiation and inflammatory response of chondrocytes. $J$ Cell Biochem 104, 1393-1406.

50. Kim HJ, Hawke N \& Baldwin AS (2006) NF-kappaB and IKK as therapeutic targets in cancer. Cell Death Differ $\mathbf{1 3}$ 738-747.

51. Perkins ND \& Gilmore TD (2006) Good cop, bad cop: the different faces of NF-kappaB. Cell Death Differ 13, 759-772.

52. Kobielak A \& Fuchs E (2006) Links between alpha-catenin, NF-kappaB, and squamous cell carcinoma in skin. Proc Natl Acad Sci U S A 103, 2322-2327.

53. Huang S, DeGuzman A, Bucana CD, et al. (2000) Level of interleukin- 8 expression by metastatic human melanoma cells directly correlates with constitutive NF-kappaB activity. Cytokines Cell Mol Ther 6, 9-17.

54. Payne AS \& Cornelius LA (2002) The role of chemokines in melanoma tumor growth and metastasis. J Invest Dermatol 118, 915-922.

55. Richmond A (2002) Nf-kappa B, chemokine gene transcription and tumour growth. Nat Rev Immunol 2, 664-674.

56. Li JJ, Rhim JS, Schlegel R, et al. (1998) Expression of dominant negative Jun inhibits elevated AP-1 and NF-kappaB transactivation and suppresses anchorage independent growth of HPV immortalized human keratinocytes. Oncogene 16, 2711-2721.

57. Dajee M, Lazarov M, Zhang JY, et al. (2003) NF-kappaB blockade and oncogenic Ras trigger invasive human epidermal neoplasia. Nature 421, 639-643.

58. Saleem M, Afaq F, Adhami VM, et al. (2004) Lupeol modulates NF-kappaB and PI3K/Akt pathways and inhibits skin cancer in CD-1 mice. Oncogene 23, 5203-5214.

59. Arora N, Bansal MP \& Koul A (2011) Azadirachta indica exerts chemopreventive action against murine skin cancer: studies on histopathological, ultrastructural changes and modulation of NF-kappaB, AP-1, and STAT1. Oncol Res 19, $179-191$ 